\title{
Effects of Different Equilibration Times on Post-Thaw Cryopreserved Semen Quality of Cattle and Buffalo Bulls
}

\author{
Adnan Khan', Rifat Ullah Khan ${ }^{1}$, Muhammad Subhan Qureshi', \\ Muhammad Mobashar ${ }^{3}$, Ali Gohar ${ }^{4}$, Shakoor Ahmad', Kamran Khan ${ }^{5}$, \\ Hamayun Khan ${ }^{1}$ and Shabana $\mathrm{Naz}^{6 *}$ \\ ${ }^{1}$ Department of Animal Health, Faculty of Animal Husbandry and Veterinary Sciences, \\ The University of Agriculture, Peshawar, Pakistan \\ ${ }^{2}$ Department of Livestock, Breeding and Genetics, Faculty of Animal Husbandry and \\ Veterinary Sciences, The University of Agriculture, Peshawar \\ ${ }^{3}$ Department of Animal Nutrition, Faculty of Animal Husbandry and Veterinary \\ Sciences, The University of Agriculture, Peshawar \\ ${ }^{4}$ College of Veterinary and Animal Husbandry, Abdul Wali Khan University, Mardan \\ ${ }^{5}$ Department of Animal Sciences, Shaheed Benazir Bhutto University, Sheringal, \\ Upper Dir, Pakistan
}

\begin{tabular}{l} 
Article Information \\
Received 24 August 2019 \\
Revised 10 October 2019 \\
Accepted 27 December 2019 \\
Available online 21 February 2021 \\
Authors' Contribution \\
\hline AK, RUK and MSQ designed and \\
conducted the study. MM, AG, SA \\
conducted lab analysis. KK, HK and \\
SN edited the paper. \\
Key words \\
Holstein friesian, Jersey, Buffalo \\
breed, Nili Ravi, Semen quality
\end{tabular}

\begin{abstract}
A B S T R A C T
Nine mature bulls were selected in three $(n=9)$ different groups (Holstein Fresian, Jersey and Nili Ravi) to find out equilibration time (T1, $2 \mathrm{~h} ; \mathrm{T} 2,6 \mathrm{~h}$ and T3, $6 \mathrm{~h}$ ) effects on different semen quality parameters. Highest sperm progressive motility, sperm plasma membrane integrity were observed in T2. It reflects high damages at T3 and T1 due to cryo shock and oxidative stress respectively. Sperm DNA integrity and $\mathrm{pH}$ were increased linearly from $\mathrm{T} 1$ to $\mathrm{T} 3$. The dead sperm percentage was significantly $(\mathrm{P}<0.01)$ low in groups with semen sample treated with $\mathrm{T} 2$ compared to other groups. Significantly $(\mathrm{P}<0.01)$ high sperm individual motility percentage was observed for T2 than T3 and T1. Sperm acrosomal integrity percentage showed significantly $((\mathrm{P}<0.01)$ high value in $\mathrm{T} 2$. It is concluded that $4 \mathrm{~h}$ equilibration time improved semen qualitative characteristics. Among the three breeds, Jersey bull semen samples showed the best quality. Equilibration time of 2 and 6 hours showed detrimental effect on the semen quality.
\end{abstract}
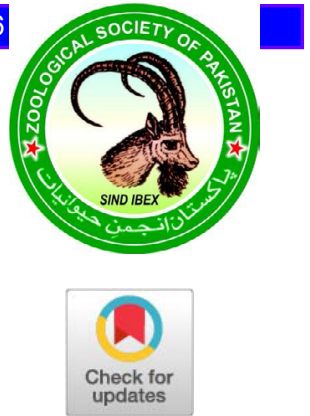

\section{INTRODUCTION}

$\mathrm{T}$ he successful cryopreservation enables spermatozoa to maintain its fertilizing ability at post thawing. During cryopreservation, the sperm should be able to maintain normal plasma membrane integrity, motility, and enzymes activity like acrosin to allow the penetration of pserm into the ovum. Fertilization ability of the spermatozoa will not be achieved in case of any disturbance in any of these functions. The major menace in maintaining these properties is due to ice crystals formation and the osmotic gradients taken up by water movement during cryopreservation process (Bushra et al., 2013).

The survivability of sperms is enhanced by equilibration time during freezing. Water within the cell is replaced with glycerol, which prevents ice crystal

\footnotetext{
* Corresponding author: shabanapervez.2000@gmail.com 0030-9923/2021/0002-0613 \$ 9.00/0

Copyright 2021 Zoological Society of Pakistan
}

formation during equilibration time and thus helps to prevent injuries to spermatozoa (Qureshi, 2011). The ideal cooling and equilibration time is that which is as quick as possible to elude effects of solution but slow enough to avoid intracellular ice formation to maintain sperm viability (Andrabi, 2009). There has been discrepancy concerning the requisite and extent of equilibration on cryopreservation and its influence on the survivability of sperm (Crespilho et al., 2012). Therefore, the study was design to address the effects of different equilibration times on post thaw semen quality of cattle and buffalo bulls.

\section{MATERIALS AND METHODS}

\section{Selection of bulls}

Nine andrologically and physically normal adult bulls of each breed including Friesian, Jersey and Nili Ravi bulls were selected for assessment of their semen quality for 4 weeks at the interval of twice a week (Monday and Thursday). 


\section{Semen collection}

Semen samples were collected early in the morning from all the selected bulls kept at Government Cattle Breeding and Dairy Farm Harichand Charsadda using artificial vagina from each bull $(n=9)$ maintaining all hygienic measures (Qureshi, 2011). Collection of two semen aliquots (total=6) were made from each bull of each breed on the same day. Semen ejaculates with motile sperm $(>60 \%)$, volume $(>1 \mathrm{~mL})$ and concentration $(>0.5$ billion/ml) from each bull were used (Ansari et al., 2011). Semen was shifted to hot water bath at $34{ }^{\circ} \mathrm{C}$ immediately after collection and was evaluated for initial qualitative and quantitative tests. Sperm concentration in semen aliquot was assessed by bovine photometer ACCUCELL (IMV, France) at $539 \mathrm{~nm}$ wave length. Each ejaculate was supplemented in single step with Tris-egg yolk-glycerol (TRIS) at $34^{\circ} \mathrm{C}$, getting the final concentration of $50 \times 10^{6} \mathrm{sperm} / \mathrm{ml}$. The semen was extended (Tris-citric egg yolk extender) soon after assessing sperm mass motility and concentration, 5-10 min after collection (Leite et al., 2010).

\section{Semen processing}

Semen samples were incubated in a water bath at $34{ }^{\circ} \mathrm{C}$ for $10 \mathrm{~min}$. after that, it was cooled to $25^{\circ} \mathrm{C}$ (room temperature), which took about $20 \mathrm{~min}$ and then cooled down to $4^{\circ} \mathrm{C}$ in $2 \mathrm{~h}$. After cooling, semen was exposed to different equilibration times $\left(2,4\right.$, and $6 \mathrm{~h}$ ) at $4^{\circ} \mathrm{C}$ (Leite $e t$ al., 2010). At the end of each equilibration time, $0.5 \mathrm{~mL}$ semen was transferred to liquid nitrogen with the help of French straw. To assess post thaw semen quality after $24 \mathrm{~h}$ of cryopreservation, the frozen semen straws were thawed in water bath at $37^{\circ} \mathrm{C}$ for 30 seconds and incubated for $6 \mathrm{~h}$ for qualitative tests (Ansari et al., 2011).

\section{Determination of sperm quality parameters}

Semen was assessed for individual motility, progressive motility and dead sperm percentage were determined according to Qureshi (2011).

\section{Determination of sperm plasma membrane integrity}

This test was performed as directed by Qureshi (2011). Briefly, $0.1 \mathrm{ml}$ of the thawed test whole semen was mixed with $1 \mathrm{ml}$ test solution [0.5 ml of D-fructose $(1.47 \%)$ and sodium citrate $(2.7 \%)$ ] and was incubated for 40 minutes at $37^{\circ} \mathrm{C}$. After incubation in hypo-osmotic solution, semen drop $(5 \mu \mathrm{l})$ was placed on a prewarmed slide. The slide was then covered with cover slip and was examined under phase contrast microscope (400X; LABOMED LX400).

\section{Determination of semen $p H$}

A thawed semen drop was spread evenly on the $\mathrm{pH}$ paper, waited for $<30$ seconds to get uniform colour of the impregnated zone. The semen color of impregnated zone comparable with $>7.0$ were considered as of basic nature and that of with $<7.0$ were considered as acidic in nature (Haugen and Grotmol, 1998).

\section{Determination of acrosomal integrity}

The dual staining technique comprising of trypan-blue and Giemsa stain was performed following protocol directed by Kovacs and Foote (1992). In this procedure, trypan-blue was used for distinguishing live and dead spermatozoa while for evaluating acrosomal membrane integrity Giemsa stain was used. For this intention, one drop of both trypan-blue $(2.0 \%)$ and semen was placed on a clean slide and mixed, air dried and fixed (formaldehyde-neutral red solution, MP Biomedicals, Eschwege, Germany)] for $5 \mathrm{~min}$. The slides were then rinsed with distill water and for $4 \mathrm{~h}$ and then dipped in Giemsa stain (MP Biomedicals, Eschwege, Germany). The Giemsa stained slides were washed with distill water, air dried and cover slips were placed on it before covering with Balsam of Canada (Merck, Darmstadt, Germany) and observed under phase contrast microscope at 1000X (LABOMED LX400).

\section{Determination of sperm DNA integrity}

Semen straw was thawed in water bath at $37{ }^{\circ} \mathrm{C} .20$ $\mu 1$ semen was mixed in $200 \mu 1 \mathrm{TNE}$ buffer (Tris $=50 \mathrm{mM}$, $\mathrm{NaCl}=140 \mathrm{mM}$, EDTA $=5 \mathrm{mM}$ ) to final concentration of approximately $2 \times 10^{6}$ spermatozoa $/ \mathrm{ml}$. From each semen sample of $20 \mu \mathrm{l}$, three smears were prepared on prewarmed clean glass slides, smeared and air dried. Carnoy's solution [methanol and glacial acetic acid (Merck, Darmstadt, Germany) in 3:1 ratio] was applied over night for the fixation of all smears. Subsequently, slides were washed with distill water, made air dried and dipped in tampon solution [(80mM citric acid (Merck, Darmstadt, Germany) and 15mM Sodium phosphate (Sigma, NY, USA), pH 2.5)] in water bath at $75^{\circ} \mathrm{C}$ for 5 minutes. After the incubation in tampon solution, acridine orange (Sigma, NY, USA), $\mathrm{pH}$ 2.5) $(0.2 \mathrm{mg} / \mathrm{ml})$ was applied for 2 minutes on processed slides. Slides were then washed with phosphate buffer saline (PBS), covered with cover slip whilst they were still soaked and evaluated under fluorescent microscope (LABOMED LX400).

\section{Statistical analysis}

Effects of equilibration times on sperm progressive motility, individual motility, acrosomal integrity, plasma membrane integrity, dead sperm, semen $\mathrm{pH}$ and DNA integrity were analyzed with the help of Statistix ( 8.1 version) for Windows using $2 \times 3 \times 2$ factorial design as described by Steel and Torrie (1997). To find the significant difference, Duncan multiple range test was used (Duncan, 1955). 


\section{RESULTS}

The results of membrane integrity, progressive motility, individual motility and acrosomal integrity in different breeds at different equiliberation times is given in Table I. The results indicated that membrane integrity, progressive motility, individual motility, acrosomal integrity increased significantly $(\mathrm{P}<0.01)$ at $4 \mathrm{~h}$ equilibration time and decreased at $2 \mathrm{~h}$. Also, Jersey has significantly $(\mathrm{P}<0.01)$ high values followed Holstein Friesian and Nili Ravi.

The result of different equilibration times on semen $\mathrm{pH}$, DNA integrity, and dead sperm of Jersey, Holstein Fresien and Nili Ravi bulls is given in Table II. The effect of Semen $\mathrm{pH}$ was significantly $(\mathrm{P}<0.01)$ high at $2 \mathrm{~h}$ equilibration time and was significantly low at $6 \mathrm{~h}$. Breed has no significant effect on seminal $\mathrm{pH}$. Sperm DNA integrity was significantly $(\mathrm{P}<0.01)$ high at $2 \mathrm{~h}$ equilibration time and was significantly low at $6 \mathrm{~h}$. Sperm DNA integrity value was significantly $(\mathrm{P}<0.01)$ high in Holstein Friesian followed by Jersey and Nili Ravi. Dead spermatozoa were significantly $(\mathrm{P}<0.01)$ high at $2 \mathrm{~h}$ equilibration time and was significantly high at $4 \mathrm{~h}$. Dead sperm percentage was significantly $(\mathrm{P}<0.01)$ high in Nili Ravi followed by Holstein Friesian and Jersey.

\section{DISCUSSION}

In this study, the effect of different equilibration times on post thaw cryo preserved semen quality of cattle and buffalo bulls were evaluated. The result of the present study indicated that $4 \mathrm{~h}$ equilibration time produced optimum results regarding semen traits. In the present study, sperm individual motility, progressive motility, membrane integrity and acrosomal integrity were significantly high for $4 \mathrm{hr}$ equilibration time which is in line with other works (Herold et al., 2006; Liete et al., 2010). Spermatozoa faced partial injuries during equilibration step of semen processing, became high post freezing and thawing. During cryopreservation, low temperature and high salt concentration are mainly responsible for destabilization of sperm plasma membranes (Holt and North, 1994). The present results which are in line with above research findings presented that sperm membrane integrity percentage of the tested semen samples was significantly $(\mathrm{P}<0.01)$ high for $4 \mathrm{~h}$ equilibration time followed by $6 \mathrm{~h}$ and the low value of membrane integrity percentage was recorded for $2 \mathrm{~h}$ equilibration time and this has been also supported in other studies (Herold et al., 2006; Liete et al., 2010).

The current research results illustrated that sperm progressive motility percentage of the tested samples was significantly highest for $4 \mathrm{~h}$ equilibration time followed by $6 \mathrm{~h}$ and the lowest value of progressive motility percentage was noted for $2 \mathrm{~h}$ equilibration time and this has been supported by many scientist (Herold et al., 2006; Liete et al., 2010). Breed effect showed that plasma membrane of buffalo sperm constitutes higher percentage of polyunsaturated fatty acids than sperm of cattle bull (Parks et al., 1992). Due to this, buffalo sperm is more vulnerable to cryo damages and oxidative stress induced during freezing and cryopreservation process than cattle spermatozoa (Kumar et al., 2011). As a result there is decrease in progressive motility percentage of buffalo spermatozoa. This is supported by the findings of present research work as progressive motility percentage was high in cattle bulls (Jersey, Holstein Friesian) than buffalo bull (Nili Ravi) spermatozoa.

The presented results in term of sperm motility was supported by the above findings as individual motility percentage of the studied semen samples was significantly highest for $4 \mathrm{~h}$ equilibration time followed by $6 \mathrm{~h}$ and the least value of individual motility percentage was recorded for $2 \mathrm{~h}$ equilibration time and this has also been supported by other works (Herold et al., 2006; Liete et al., 2010). Buffalo spermatozoa lose their motility following equilibration, freezing and thawing processes (Kakar and Anand, 1981). Moreover, a significant loss in buffalo sperm motility occurs following equilibration time than cattle sperms (Tuli et al., 1981). Similar pattern was supported by our presented data as cattle sperm (Jersey and Holstein Friesian) had high individual motility than Buffalo sperm motility (Nili Ravi).

The presented results showed the symmetrical relation between different equilibration times and acrosomal integrity percentage of the studied semen samples as it was significantly high for $4 \mathrm{~h}$ equilibration time followed by $6 \mathrm{~h}$ and the least value of sperm membrane integrity percentage was recorded for $2 \mathrm{~h}$ equilibration time and this is in line with other works (Herold et al., 2006; Andrabi, 2009). Acrosomal damages were high for $2 \mathrm{~h}$ equilibration time than $4 \mathrm{~h}$ (Niasari- Naslaji et al., 2006; Liete et al., 2010). Breed effect showed that plasma membrane of buffalo sperm constitutes higher percentage of polyunsaturated fatty acids than sperm of cattle bull (Parks et al., 1992). Due to this buffalo sperm is more vulnerable to cryo damages and oxidative stress induced during the process of freezing and cryopreservation than cattle spermatozoa (Kumar et al., 2011). As a result, there is a decrease in acrosomal integrity percentage of buffalo spermatozoa. These relations were supported by our presented data having high acrosomal integrity percentage for cattle (Jersey, Holstein Friesian) than buffalo (Nili Ravi) sperms. 
Table I. Mean \pm SE of membrane integrity, progressive motility, individual motility and acrosomal integrity of Jersey, Holstein, Friesian and Nilli Ravi bulls at different equilibration times.

\begin{tabular}{llllll}
\hline $\begin{array}{l}\text { Equilibra- } \\
\text { tion time }\end{array}$ & Breed & $\begin{array}{l}\text { Membrane integrity } \\
(\%)\end{array}$ & $\begin{array}{l}\text { Progressive motility } \\
(\%)\end{array}$ & $\begin{array}{l}\text { Individual motility } \\
(\%)\end{array}$ & $\begin{array}{l}\text { Acrosomal integrity } \\
(\%)\end{array}$ \\
\hline \multirow{2}{*}{$2 \mathrm{H}$} & Jersey & $40.91^{\mathrm{h}} \pm 0.49$ & $11.00^{\mathrm{g}} \pm 0.32$ & $40.54^{\mathrm{g}} \pm 0.51$ & $37.9^{\mathrm{g}} \pm 0.47$ \\
& HF & $40.5^{\mathrm{g}} \pm 0.45$ & $9.33^{\mathrm{h}} \pm 0.31$ & $40.16^{\mathrm{g}} \pm 0.44$ & $31.04^{\mathrm{h}} \pm 0.48$ \\
& Nili Ravi & $37.12^{\mathrm{i}} \pm 0.31$ & $7.45^{\mathrm{i}} \pm 0.24$ & $38.2^{\mathrm{g}} \pm 0.42$ & $25.2^{\mathrm{i}} \pm 0.41$ \\
$4 \mathrm{H}$ & Jersey & $70.95^{\mathrm{a}} \pm 0.33$ & $33.45^{\mathrm{a}} \pm 0.31$ & $74.16^{\mathrm{a}} \pm 0.23$ & $68.41^{\mathrm{a}} \pm 0.32$ \\
& HF & $69.20^{\mathrm{b}} \pm 0.31$ & $31.70^{\mathrm{b}} \pm 0.35$ & $71.08^{\mathrm{b}} \pm 0.29$ & $63.20^{\mathrm{b}} \pm 0.31$ \\
& Nili Ravi & $66.95^{\mathrm{c}} \pm 0.38$ & $26.33^{\mathrm{c}} \pm 0.36$ & $68.91^{\mathrm{c}} \pm 0.38$ & $59.29^{\mathrm{c}} \pm 0.26$ \\
$6 \mathrm{H}$ & Jersey & $51.79^{\mathrm{d}} \pm 0.33$ & $21.16^{\mathrm{d}} \pm 0.29$ & $54.41^{\mathrm{d}} \pm 0.32$ & $50.83^{\mathrm{d}} \pm 0.37$ \\
& HF & $49.91^{\mathrm{e}} \pm 0.41$ & $19.83^{\mathrm{e}} \pm 0.29$ & $51.70^{\mathrm{e}} \pm 0.35$ & $47.66^{\mathrm{e}} \pm 0.44$ \\
& Nili Ravi & $48.70^{\mathrm{f}} \pm 0.32$ & $17.87^{\mathrm{f}} \pm 0.27$ & $50.54^{\mathrm{f}} \pm 0.38$ & $42.12^{\mathrm{g}} \pm 0.35$ \\
P Value & Breed & 0.0000 & 0.0000 & 0.0000 & 0.0000 \\
& Time & 0.0000 & 0.0000 & 0.0000 & 0.0000 \\
& Breed*Time & 0.0000 & 0.0000 & 0.0001 & 0.0000 \\
\hline
\end{tabular}

Mean values bearing different superscripts in a column differ significantly $(\mathrm{P}<0.05)$

Table II. Mean \pm SE of semen pH, DNA Integrity and dead sperm of Jersey, Holstein Fresien and Nili Ravi bulls at different equilibration times.

\begin{tabular}{lllll}
\hline Equilibration Time & Breed & pH & DNA integrity (\%) & Dead sperm (\%) \\
\hline $2 \mathrm{H}$ & Jersey & $6.82^{\mathrm{a}} \pm 0.01$ & $95.91^{\mathrm{a}} \pm 0.14$ & $50.91^{\mathrm{b}} \pm 0.55$ \\
& HF & $6.84^{\mathrm{a}} \pm 0.01$ & $94.70^{\mathrm{b}} \pm 0.18$ & $52.37^{\mathrm{a}} \pm 0.56$ \\
& Nili Ravi & $6.85^{\mathrm{a}} \pm 0.01$ & $94.75^{\mathrm{b}} \pm 0.19$ & $53.29^{\mathrm{a}} \pm 0.67$ \\
$4 \mathrm{H}$ & Jersey & $6.47^{\mathrm{b}} \pm 0.01$ & $90.54^{\mathrm{c}} \pm 0.24$ & $19.70^{\mathrm{b}} \pm 0.32$ \\
& HF & $6.40^{\mathrm{c}} \pm 0.01$ & $90.75^{\mathrm{c}} \pm 0.21$ & $22.20^{\mathrm{g}} \pm 0.32$ \\
& Nili Ravi & $6.45^{\mathrm{b}} \pm 0.02$ & $90.20^{\mathrm{c}} \pm 0.24$ & $26.08^{\mathrm{f}} \pm 0.35$ \\
$6 \mathrm{H}$ & Jersey & $5.90^{\mathrm{d}} \pm 0.01$ & $87.79^{\mathrm{d}} \pm 0.25$ & $37.54^{\mathrm{e}} \pm 0.28$ \\
& HF & $5.91^{\mathrm{d}} \pm 0.01$ & $88.16^{\mathrm{d}} \pm 0.24$ & $39.50^{\mathrm{d}} \pm 0.44$ \\
& Nili Ravi & $5.90^{\mathrm{d}} \pm 0.01$ & $84.87^{\mathrm{a}} \pm 0.22$ & $42.16^{\mathrm{c}} \pm 0.31$ \\
P Value & Breed & 0.5977 & 0.0000 & 0.0000 \\
& Time & 0.0000 & 0.0000 & 0.0000 \\
\hline
\end{tabular}

Mean values bearing different superscript in a column differ significantly $(\mathrm{P}<0.05)$

Semen storage for long equilibration time may decrease post freezing seminal $\mathrm{pH}$ because of lactic acid production from fructose and post freezing semen $\mathrm{pH}$ may increase, when it is stored for short equilibration time as production of lactic acid formation will be low (Qureshi, 2011; Andrabi et al., 2009). This is supported by present research findings as seminal of the studied semen samples was significantly high for $2 \mathrm{~h}$ equilibration time followed by $4 \mathrm{~h}$ and the least value of $\mathrm{pH}$ was recorded for $6 \mathrm{~h}$ equilibration time.

Because of lipid peroxidation of the plasma membrane
(Kankofer et al., 2005), the process of semen dilution, cooling, equilibration, freezing and thawing speed up the production of reactive oxygen species molecules (Mehr et al., 2013). These unnecessary reactive oxygen species molecules can damage the sperm DNA integrity of cattle and buffalo semen (Kumaresan et al., 2006, 2005; Garg et al., 2008). In the presented data, our findings are in line with the results for above studies on bovine semen. Buffalo semen protects spermatozoa from oxidative stress due to its both enzymatic and non-enzymatic antioxidant mechanism (Andrabi, 2009; Khan, 2011). Plasma 
membrane of buffalo sperm constitutes higher percentage of polyunsaturated fatty acids than sperm of cattle bull (Parks et al., 1992). Due to this buffalo sperm is more vulnerable to and oxidative stress induced during freezing and cryopreservation than cattle spermatozoa (Kumar et al., 2011), results in high DNA damage for buffalo after thawing (Parks et al., 1992).

Effective freezing procedure requires determination of proper equilibration time which suggests that if equilibration time is low then huge amount of water is left inside the cell resulting in cell death due to ice crystal formation which damages the membrane may lead to sperm death. If the equilibration time is too high then the cells may undergo excessive shrinkage and extra solute contact. For that reason the ideal equilibration time is that which is as quick as possible to elude effects of solution, but slow enough to avoid intracellular ice formation to maintain sperm viability (Andrabi, 2009).

\section{CONCLUSION}

Equilibration time of $4 \mathrm{~h}$ showed best post thaw cryopreserved semen quality characteristics in all breeds. Jersey bulls showed the best quality attributes at 2, 4, and $6 \mathrm{~h}$ of equilibration. Sperm membrane integrity showed positive correlation with acrosomal integrity, progressive motility, individual motility and was inversely related the dead sperm percentage, DNA integrity and seminal $\mathrm{pH}$.

\section{Statement of conflict of interest}

The author have declared no conflict of interset.

\section{REFERENCES}

Andrabi, S.M.H., 2009. Factors affecting the quality of cryopreserved buffalo (Bubalus bubalis) bull spermatozoa. Rep. Dom. Anim., 44: 552-569. https://doi.org/10.1111/j.1439-0531.2008.01240.x

Ansari, M.S, Rakha, B.A., Ullah, N., Andrabi, S.M.H., Khalid, M. and Akhter, S., 2011. Effect of L-cysteine in tris-citric egg yolk extender on post thaw quality of Nili-Ravi buffalo (Bubalus bubalis) bull spermatozoa. Pakistan J. Zool., 43: 41-47.

Bushra, A.R, Hussain, I., Akhter, S., Ullah, N., Andrabi, S.M.H. and Ansari, M.S., 2013. Evaluation of Triscitric acid, skim milk and sodium citrate extenders for liquid storage of Punjab Urial (Ovis vignei punjabiensis) spermatozoa. Rep. Biol., 13: 238 -242. https://doi.org/10.1016/j.repbio.2013.06.004

Crespilho, A.M, Papa, F.O., Santos, M.P. and Filho, M.F., 2012. Use of cooled bull semen as a strategy to increase the pregnancy rate in fixed-time artificial insemination programs-case report. Am. J. Anim. Vet. Sci., 7: 175-179. https://doi.org/10.3844/ ajavsp.2012.175.179

Duncan, D.B., 1955. Multiple ranges and multiple F-test. Biometrics, 1: 1-42. https://doi. org/10.2307/3001478

Garg, A, Kumaresan, A. and Ansari, M., 2008. Effect of hydrogen peroxide on fresh and cryopreserved buffalo sperm functions during incubation at $37^{\circ} \mathrm{C}$ in vitro. Rep. Dom. Anim., 10: 1439-1445.

Haugen, T.B. and Grotmol, T. 1998. pH of human semen. Int. J. Androl., 21: 105. https://doi.org/10.1046/ j.1365-2605.1998.00108.x

Herold, F.C, Haas, K.D., Colenbrander, B. and Gerber, D., 2006. Comparison of equilibration times when freezing epididymal sperm from African buffalo (Syncerus caffer) using Triladyl. Theriogenology, 66: $1123-1130 . \quad \mathrm{https}: / /$ doi.org/10.1016/j. theriogenology.2006.03.007

Holt, W.V. and North, R.D., 1994. Effects of temperature and restoration of osmotic equilibrium during thawing on the induction of plasma membrane damage in cryopreserved ram spermatozoa. Biol. Rep., 51: 414-424. https://doi.org/10.1095/ biolreprod51.3.414

Khan, R.U., 2011. Antioxidants and poultry semen quality. World's Poult. Sci. J., 67: 297-308. https:// doi.org/10.1017/S0043933911000316

Kakar, S.S. and Anand, S.R., 1981. Changes in adenosine 5-triphosphate, adenylate energy charge and adenosine 35-cyclic monophosphate during the freezing of buffalo semen. J. Rep. Fert., 62: 543548. https://doi.org/10.1530/jrf.0.0620543

Kankofer, M., Kolm, G. and Aurich, G., 2005. Activity of glutathione peroxidase, superoxide dismutase and catalase and lipid peroxidation intensity in stallion semen during storage at $5^{\circ} \mathrm{C}$. Theriogenology, 63: 1354-1365. https://doi. org/10.1016/j.theriogenology.2004.07.005

Kovacs, A. and Foote, R.H., 1992. Viability and acrosome staining of bull, boar and rabbit spermatozoa. Biotech. Histochem., 67: 119-124. https://doi.org/10.3109/10520299209110020

Kumar, R., Mohanarao, G.J. and Arvind-Atreja, S.J., 2011. Freeze-thaw induced genotoxicity in buffalo (Bubalus bubalis) spermatozoa in relation to total antioxidant status. Mol. Biol. Rep., 38: 1499-1506. https://doi.org/10.1007/s11033-010-0257-1

Kumaresan, A, Ansari, M.R., Garg. A., and Andkataria, M., 2006. Effect of oviductal proteins on sperm functions and lipid peroxidation levels during cryopreservation in buffaloes. Rep. Dom. 
Anim., 93: 264-257. https://doi.org/10.1016/j. anireprosci.2005.06.030

Kumaresan, A, Ansari, M.R. and Garg, A., 2005. Modulation of post thaw sperm functions with oviductal proteins in buffaloes. Anim. Rep. Sci., 90: 73-84. https://doi.org/10.1016/j. anireprosci.2005.01.009

Leite, T.G., Filhoa, V.R.V., Arrudab, R.P., Andrade, A.F.C., Emericka, L.L., Zaffalonb, F.G. and Andre, J., 2010. Effects of extender and equilibration time on post-thaw motility and membrane integrity of cryopreserved Gyr bull semen evaluated by CASA and flow cytometry. Anim. Rep. Sci., 120: 31-38. https://doi.org/10.1016/j.anireprosci.2010.04.005

Mehr, M.R.A, Chambary, B. and Hossein-Zadeh, N.G., 2013. Effect of different diluents and storage time on field fertility of cooled ram semen after vaginal insemination. Small Rumin. Res., 115: 82- 85. https://doi.org/10.1016/j.smallrumres.2013.09.004

Niasari-Naslaji, A., Mosaferi, S., Bahmani, N., Gharahdaghi, A.A., Abarghani, A., Ghanbari, A. and Gerami, A., 2006. Effectiveness of a tris-based extender (SHOTOR diluents) for the preservation of Bactrian camel (Camelus bactrianus) semen. Cryobiology, 53: 12-21. https://doi.org/10.1016/j. cryobiol.2006.03.006

Parks, J.E. and Graham, J.K., 1992. Effects of cryopreservation procedures on sperm membranes. Theriogenology, 38: 210-223. https://doi. org/10.1016/0093-691X(92)90231-F

Qureshi, M.S. 2011. preparation of semen extender, processing of semen and storage. In: Reproductive physiology of domestic animals. Higher Education Commission Islamabad. pp. 127-129.

Steel, R.C, Torrie, J. and Dickey, A., 1997. Principles and procedures of statistics. Third edition. McGraw Hill Book Co. Inc. New York.

Tuli, R.K, Singh, M. and Matharoo, J.S., 1981. Effect of different equilibration times and extenders on deep freezing of buffalo semen. Theriogenology, 16: 99-104. https://doi.org/10.1016/0093691X(81)90118-7 